\title{
Atividade alelopática de extrato acetato-etílico de folhas de Solanum cernuum Vell ${ }^{1}$
}

\author{
Allelopathic action of ethyl-acetate extract of the leaves of Solanum cernuum Vell
}

\author{
Luiz Gustavo André Oliveira ${ }^{2}$, Fernanda Farias Duque ${ }^{3}$, Valdenir José Belinelo ${ }^{3}$, Edilson Romais Schmildt ${ }^{4 *}$ e \\ Marcelo Suzart de Almeida ${ }^{5}$
}

\begin{abstract}
RESUMO - O objetivo deste trabalho foi avaliar a atividade alelopática do extrato com acetato-etílico das folhas de Solanum cernuum Vell (Solanaceae) em relação ao efeito inibitório da germinação de sementes e vigor de plântulas de Sorghum bicolor L. (sorgo), Lactuca sativa L. (alface) e Bidens pilosa L. (picão preto). Foi avaliada a atividade fitotóxica do extrato com acetato-etílico nas concentrações de 0,$00 ; 31,25 ; 62,50 ; 125,00 ; 250,00 ; 500,00 ; 750,00$ e 1.000,00 $\mathrm{mg} \mathrm{L}^{-1}$. As variáveis analisadas foram porcentagem de germinação, índice de velocidade de germinação, comprimento de parte aérea e de raízes, e, massa seca de plântulas. Os resultados mostraram efeito fitotóxico do extrato com acetato-etílico de S. cernuum sobre sorgo, alface e picão preto em pelo menos uma das variáveis analisadas. Para picão preto, todas as variáveis, exceto a massa seca, sofreram reduções significativas $(p<0,05)$. Há efeitos fitotóxicos do extrato com acetato-etílico de Solanum cernuum Vell sobre a germinação de sementes e o vigor de plântulas de sorgo, alface e picão preto. Dentre as espécies estudadas, picão preto é a mais sensível, com redução de $69 \%$ no comprimento da parte aérea e $88 \%$ no comprimento de raízes na presença de extrato de $S$. cernuum a $100 \mathrm{mg} \mathrm{L}^{-1}$.
\end{abstract}

Palavras-chave: Alelopatia. Sorgo. Alface. Picão Preto.

\begin{abstract}
The aim of this study was to evaluate the allelopathic action of an ethyl-acetate extract of the leaves of Solanum cernuum Vell (Solanaceae) relative to the inhibitory effect on seed germination and seedling vigour in Sorghum bicolor L. (sorghum), Lactuca sativa L. (lettuce) and Bidens pilosa L. (Spanish needle). The phytotoxic activity of the ethyl acetate extract was evaluated at concentrations of $0.00 ; 31.25 ; 62.50 ; 125.00 ; 250.00 ; 500.00 ; 750.00$ and $1000.00 \mathrm{mg} \mathrm{L}^{-1}$. The variables analyzed were: percentage of germination; germination speed index; length of shoot and root; and seedling dry weight. The results showed a phytotoxic effect for the ethyl acetate extract of $S$. cernuum on sorghum, lettuce and Spanish needle for at least one of the variables analysed. For Spanish needle, all the variables except dry mass suffered significant reductions $(p<0.05)$. There are phytotoxic effects for the ethyl acetate extract of Solanum cernuum Vell on seed germination and seedling vigour in sorghum, lettuce and Spanish needle. From the species studied, Spanish needle is the most sensitive, with a 69\% reduction in shoot length and an $88 \%$ reduction in root length in the presence of the extract of $S$. cernuum at $100 \mathrm{mg} \mathrm{L}^{-1}$.
\end{abstract}

Key words: Allelopathy. Sorghum bicolor. Lactuca sativa. Bidens pilosa.

\footnotetext{
*Autor para correspondência

${ }^{1}$ Recebido para publicação em 14/08/2011; aprovado em 27/12/2012

Pesquisa realizada com recursos financeiros do CNPq e da FAPES

${ }^{2}$ Departamento de Ciências da Saúde, Universidade Federal do Espírito Santo, São Mateus-ES, Brasil, luiz_oliveira28@hotmail.com

${ }^{3}$ Programa Pós-Graduação Mestrado em Agricultura Tropical, Fitoquímica, Universidade Federal do Espírito Santo, São Mateus-ES, Brasil, fernandaduque86@gmail.com, belinelo@pq.cnpq.br

${ }^{4}$ Programa de Pós-Graduação Mestrado em Agricultura Tropical, Melhoramento de Plantas, Universidade Federal do Espírito Santo, São Mateus-ES, Brasil, edilson@npd.ufes.br

${ }^{5}$ Programa de Pós-Graduação Mestrado em Agricultura Tropical, Forragicultura e Pastagens, Universidade Federal do Espírito Santo, São Mateus-ES, Brasil, msuzart_7@hotmail.com
} 


\section{INTRODUÇÃO}

A alelopatia é um campo que vem sendo largamente pesquisado na atualidade, visto que muitos herbicidas são utilizados de forma inadequada no campo e não apresentam sua eficácia contras certas ervas daninhas, tornando-as resistentes a algumas classes desses herbicidas, gerando o efeito de tolerância (CARMO; LIMA; TAKAKI, 2007; MAGIERO, 2009).

Uma das primeiras definições de alelopatia foi feita por Rice (1984) como sendo a capacidade de vegetais, superiores ou inferiores, de produzir substâncias químicas que influenciavam no crescimento de outras espécies ao seu redor como outras plantas e microrganismos, podendo ser de ação direta ou indireta, e estimuladora ou inibidora do crescimento. As indústrias buscam na alelopatia fontes de novos pesticidas mais econômicos, menos tóxicos e mais seletivos a fim de aumentar a produção agrícola evitando ervas daninhas e insetos nos cultivos (BORGES et al., 2007; BRASS, 2009).

Os metabólitos secundários são os grandes responsáveis pelo efeito alelopático na natureza, visto que são importantes na defesa contra predadores naturais das plantas ou raios ultravioletas. Vários compostos do metabolismo secundário já foram identificados em extratos de plantas tais como compostos fenólicos simples e heterosídicos, cumarinas, xantonas, flavonóides, taninos, saponinas e compostos de enxofre e alcalóides (HAIDA et al., 2010; JÁCOME et al., 2004).

O tipo de solvente utilizado para a extração influencia nos efeitos alelopáticos como já foi descrito por Belinelo et al. (2008) que verificaram que à medida que se aumentava a polaridade do solvente, também se aumentava o efeito inibitório sobre as sementes de sorgo, o que se verifica pela presença de grupos hidroxilas e carbonilas presentes na planta estudada. O Solanum cernuun Vell pertence à família Solanaceae tendo como nome popular panacéia ou barba de bode, sendo encontrado em áreas da Mata Atlântica remanescentes em Minas Gerais e Espírito Santo (COSTA, 2004).

$\mathrm{O}$ picão preto (Bidens pilosa) está presente em praticamente todo o território brasileiro, porém seu aumento é acentuado nas regiões agrícolas do sul e centro-este, sendo considerada uma das principais ervas daninhas, a qual tem sido combatida principalmente por pesticidas sintéticos (AZAMBUJA et al., 2010; FERREIRA; SOUZA; FARIA., 2007; FERREIRA et al., 2010).

Este trabalho teve como objetivo analisar a atividade alelopática do extrato em acetato-etílico de Solanum cernuun Vell, sobre sementes de Sorghum bicolor (L.) Moench (sorgo), Lactuca sativa L. (alface) e Bidens pilosa $\mathrm{L}$. (picão preto), analisando atividade inibitória na germinação de sementes e no vigor das plântulas.

\section{MATERIAL E MÉTODOS}

\section{Material vegetal}

Solanum cernuum Vell (Solanaceae) foi cultivado no Horto de Plantas Medicinais do Centro Comunitário Franco Rossetti, Pedro Canário, ES. Após coleta, as folhas foram transportadas para o laboratório de farmacognosia do Centro Universitário Norte do Espírito Santo onde procedeu-se a secagem, extração e testes alelopáticos. As folhas foram secas em estufa de secagem a $40 \pm 5^{\circ} \mathrm{C}$, e posteriormente moídas até obter um pó fino, que foi armazenado em recipiente de vidro hermeticamente fechado.

\section{Obtenção do extrato orgânico}

O extrato do Solanum cernuun Vell foi obtido com aparelho de Soxhlet, no qual 50 gramas de pó das folhas foram colocados no aparelho e, submetidos a extração com acetato-etílico, em duplicata. Em seguida o acetato-etílico foi recuperado sob pressão reduzida em evaporador rotatório, obtendo-se extrato acetato-etílico liofilizado com $3,8 \%$ de rendimento médio.

\section{Testes de Germinação}

O efeito alelopático foi realizado por meio dos testes de germinação de sementes e vigor de plântulas de Sorghum bicolor L. (sorgo), Lactuca sativa L. (alface) e Bidens pilosa L. (picão-preto) de acordo com a literatura (BRASIL, 2009). O extrato acetato-etílico foi diluído nas concentrações de $1.000 ; 750 ; 500 ; 250 ; 125 ; 62,5$ e $31,25 \mathrm{mg} \mathrm{L}^{-1}$. Os experimentos foram conduzidos em placas de Petri de $10 \mathrm{~cm}$ de diâmetro, contendo duas folhas de papel de filtro. Cada placa recebeu três mililitros da solução do extrato; após o extrato adsorvido no papel e evaporado o acetato-etílico, foram adicionados três mililitros de água destilada e doze sementes da planta teste, previamente esterilizadas por imersão, durante, 10 minutos, em solução aquosa a $2 \%$ de hipoclorito de sódio. Para os tratamentos controle foram adicionados três mililitros do solvente e após sua evaporação, foram acrescidos três mililitros de água destilada e doze sementes da planta teste, previamente esterilizadas. As placas foram incubadas a $25^{\circ} \mathrm{C}$, sob luz fluorescente $(8 \times 40 \mathrm{~W})$, por um período de 12 dias, quando os comprimentos das raízes e parte aérea foram medidos e calculado o índice de velocidade de germinação (IVG) segundo Maguire (1962), porcentagem de germinação e a massa seca das plântulas. As porcentagens de inibição foram calculadas com base nos dados obtidos nos tratamentos controle, realizados sem extratos e mantidas as outras condições descritas.

$\mathrm{O}$ teor de umidade das sementes em base úmida foi de $12,6 \%$ para sorgo, $6,7 \%$ para alface e $12,3 \%$ para picão preto, determinado pelo método da estufa a $105 \pm 3{ }^{\circ} \mathrm{C}$ por 24 horas (BRASIL, 2009), antes da submissão dos tratamentos. 
Os testes foram realizados no delineamento inteiramente casualizado, com cinco repetições de 12 sementes cada. As médias foram submetidas à análise de variância e posterior análise de regressão, com ajuste da curva de acordo com a significância estatística $(\mathrm{p}<0,05)$ dos coeficientes do modelo.

\section{RESULTADOS E DISCUSSÃO}

O teste $\mathrm{F}$ da análise de variância revelou que os efeitos significativos entre as médias dos tratamentos ocorreram nas variáveis germinação, índice de velocidade de germinação e comprimento da parte aérea para as três espécies estudadas (Tabela 1). Para a variável comprimento de raízes houve efeito significativo para sorgo e picão preto.

Na Figura 1 observa-se inibição da germinação (G) na presença do extrato acetato-etílico de Solanum cernuum. O efeito fitotóxico foi mais acentuado em Bidens pilosa que teve redução de $50 \%$ na $\mathrm{G}$ com uso de extrato a $200 \mathrm{mg} \mathrm{L}^{-1}$. Para Sorghum bicolor a redução de $50 \%$ da $\mathrm{G}$ ocorreu com uso de extrato a $1.000 \mathrm{mg} \mathrm{L}^{-1}$. A fitotoxidez foi menos pronunciada em Lactuca sativa, ocorrendo redução de cerca de $10 \%$ na $\mathrm{G}$ com extrato a $1.000 \mathrm{mg} \mathrm{L}^{-1}$. Redução na $\mathrm{G}$ também foi observada por Hoffmann et al. (2007) em sementes de Lactuca sativa e Bidens pilosa com extrato aquoso
Figura 1 - Germinação de sementes de Sorghum bicolor L., Lactuca sativa $\mathrm{L}$. e Bidens pilosa $\mathrm{L}$. submetidas a diferentes concentrações de extrato acetato-etílico de folhas de Solanum cernuum

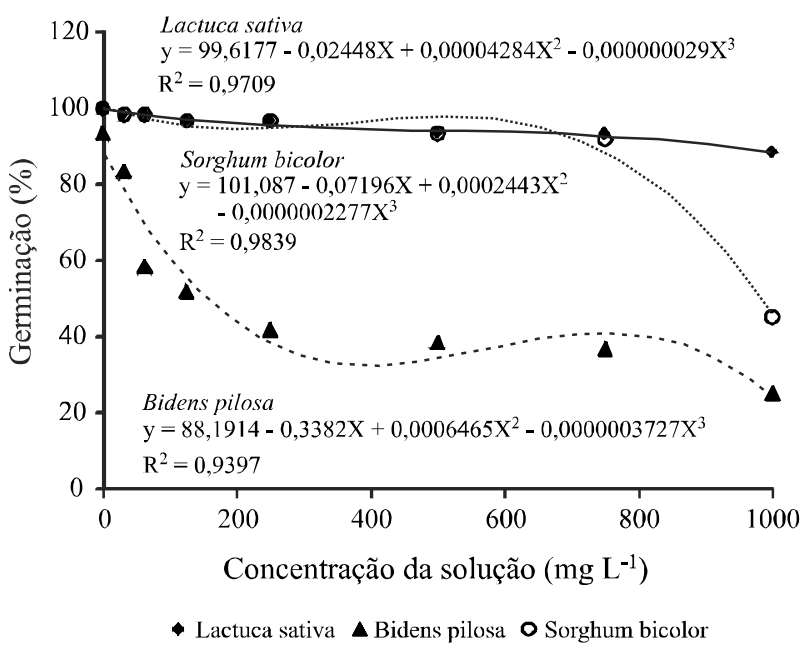

de Nerium oleander L. Souza et al. (2005) verificaram o mesmo efeito quando sementes de Casearia sylvestris Sw e Luchea divaricata Mart. Et Zuce foram tratadas com extratos aquosos de Mikania glomerata Spring. Azambuja et al. (2010) em experimento realizado com sementes de alface e picão preto, observaram que o extrato aquoso de Plectranthus barbatus Andrews,

Tabela 1 - Resumo da análise de variância da germinação (G) e índice de velocidade de germinação (IVG) das sementes, e comprimento da parte aérea (CPA), comprimento da raiz (CR), massa seca (MS) de plântulas de Sorghum bicolor, Latuca sativa e Bidens pilosa submetidas a diferentes concentrações de extrato acetato-etílico de folhas de Solanum cernuиm

\begin{tabular}{|c|c|c|c|c|c|c|}
\hline \multirow{2}{*}{ Fontes de Variação } & \multirow{2}{*}{ GL } & \multicolumn{5}{|c|}{ Quadrados Médios para Sorghum bicolor } \\
\hline & & $\mathrm{G}(\%)$ & IVG & $\mathrm{CPA}(\mathrm{mm})$ & $\mathrm{CR}(\mathrm{mm})$ & MS (mg) \\
\hline Tratamentos & 7 & $1690,76^{* *}$ & $223,32 * *$ & $390,05 * *$ & $5288,99 * *$ & $11050,52^{\mathrm{ns}}$ \\
\hline Resíduo & 32 & 195,17 & 24,86 & 68,53 & 150,11 & 4849,99 \\
\hline C.V. $(\%)$ & 15,52 & 15,46 & 21,33 & 24,80 & 8,23 & \\
\hline \multirow{2}{*}{ Fontes de Variação } & \multirow{2}{*}{ GL } & \multicolumn{5}{|c|}{ Quadrados Médios para Latuca sativa } \\
\hline & & $\mathrm{G}(\%)$ & IVG & $\mathrm{CPA}(\mathrm{mm})$ & $\mathrm{CR}(\mathrm{mm})$ & $\mathrm{MS}(\mathrm{mg})$ \\
\hline Tratamentos & 7 & $71,09^{*}$ & $9,93 *$ & $167,83 * *$ & $82,53^{\text {ns }}$ & $2,09^{\text {ns }}$ \\
\hline Resíduo & 32 & 27,73 & 3,49 & 43,26 & 46,45 & 2,12 \\
\hline $\mathrm{CV}(\%)$ & 5,51 & 5,58 & 17,86 & 18,34 & 7,53 & \\
\hline \multirow{2}{*}{ Fontes de Variação } & \multirow{2}{*}{ GL } & \multicolumn{5}{|c|}{ Quadrados Médios para Bidens pilosa } \\
\hline & & $\mathrm{G}(\%)$ & IVG & $\mathrm{CPA}(\mathrm{mm})$ & $\mathrm{CR}(\mathrm{mm})$ & MS (mg) \\
\hline Tratamentos & 7 & $2834,77 * *$ & $174,08 * *$ & $1590,99 * *$ & $580,97 * *$ & $62,64^{\text {ns }}$ \\
\hline Resíduo & 32 & 108,61 & 4,73 & 49,29 & 18,89 & 48,63 \\
\hline C.V. (\%) & 19,46 & 19,46 & 23,83 & 40,76 & 13,61 & \\
\hline
\end{tabular}

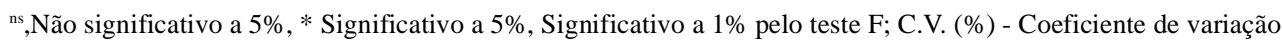


na concentração de $25 \%$ reduziu significativamente a porcentagem de germinação, enquanto Haida et al. (2010) verificaram que o infuso aquoso a $30 \%$ de Achillea millefolium L. proporcionou uma redução na porcentagem de germinação de sementes de alface. Teixeira, Araújo e Carvalho (2004) observaram que a mucuna preta atingiu redução de $35 \%$ na germinação ao ser tratada com extrato aquoso de Crotalaria juncea L. Rosado et al. (2009) quando usaram extrato aquoso de Ocimum basilicum L. observaram inibição da germinação de sementes de alface, tomate e melissa a partir das concentrações de 0,1 e $1,0 \%(\mathrm{v} / \mathrm{v})$.

A Figura 2 representa o índice de velocidade de germinação (IVG) das sementes de sorgo, alface e picão preto sob a ação do extrato com acetato-etílico de Solanum cernuum Vell (Solanaceae). Para as espécies alface e sorgo, até a concentração de $500 \mathrm{mg} \mathrm{L}^{-1}$ não ocorrem variações significativas $(\mathrm{P}<0,05)$, no entanto em picão preto, o IVG é reduzido a cerca de $50 \%$ com extrato a $145 \mathrm{mg} \mathrm{L}^{-1}$. Em outros estudos (CORSATO et al., 2010; RICKLI et al., 2011) também se verificaram reduções significativas na germinação e no IVG de sementes de picão preto com baixa concentração de extrato. Corsato et al. (2010) com extrato aquoso de girassol (Helianthus annus L.), verificaram redução de mais de $70 \%$ de G e IVG com extrato a $20 \%$. Rickli et al. (2011) com extrato aquoso de nim (Azadirachta indica A. Juss.), verificaram que ocorreu redução de mais de $50 \%$ na $\mathrm{G}$ e no IVG em picão preto com extrato a $40 \%$, enquanto em alface ocorreu com extrato a $80 \%$.

Figura 2 - Índice de velocidade de germinação (IVG) de sementes de Sorghum bicolor L., Lactuca sativa L. e Bidens pilosa L. submetidas a diferentes concentrações de extrato acetato-etílico de folhas de Solanum cernuum

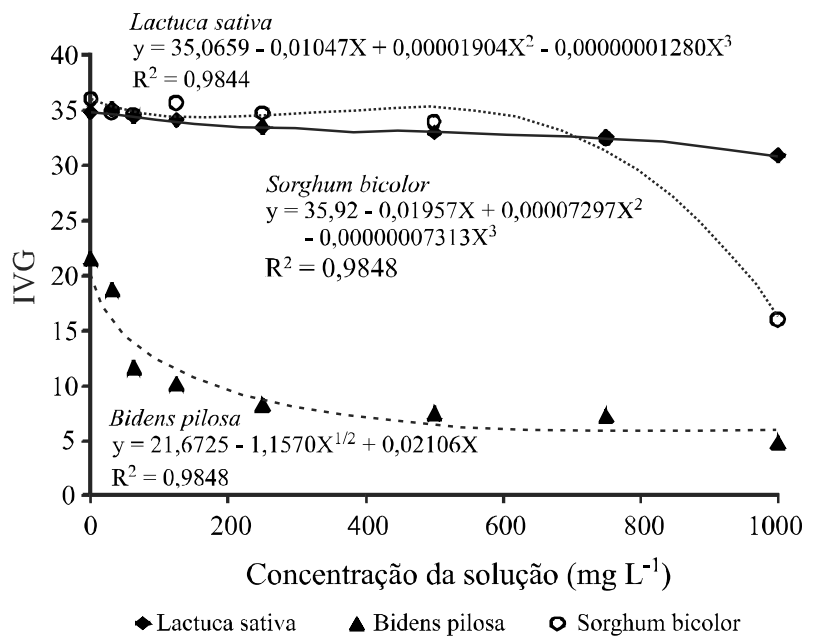

O extrato com acetato-etílico de Solanum cernuum mostrou redução da parte aérea para as três espécies em estudo. Esta redução foi mais pronunciada em Bidens pilosa, chegando a redução de $69 \%$ com extrato a $100 \mathrm{mg} \mathrm{L}^{-1}$ (Figura 3). A redução da parte aérea na presença do extrato foi acompanhada do efeito alelopático de aumento do diâmetro dos hipocótilos em algumas plântulas. Machado, Pizzolati e Bringhente (2003) relataram reduções de $70 \%$ no hipocótilo de plântulas de alface pelo tratamento das sementes com soluções a $5 \%$ dos extratos de Zantedeschia aethiopica, Ruta graveolens, Sansevieria trifasciata e Allamanda cathartica.

Figura 3 - Comprimento da parte aérea de Sorghum bicolor L., Lactuca sativa L. e Bidens pilosa L. submetido a diferentes concentrações de extrato acetato-etílico de folhas de Solanum cernuum

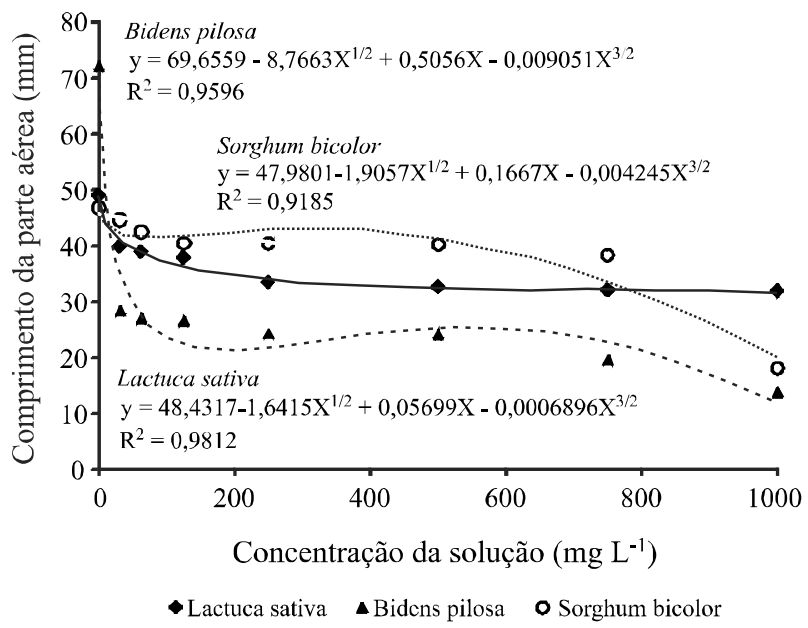

O comprimento das raízes (Figura 4) submetidas ao extrato com acetato-etílico de Solanum cernuum não mostrou variação para Lactuca sativa em relação ao controle, mas apresentou fitotoxicidade para Sorghum bicolor e Bidens pilosa com redução de 71 e $88 \%$, respectivamente, com extrato a $100 \mathrm{mg} \mathrm{L}^{-1}$, pelo modelo cúbico raiz. Verificou-se que algumas plântulas apresentaram aumento no diâmetro das raízes, o que contribuiu para os maiores valores dos coeficientes de variação para esta variável (Tabela 1). Segundo Hoffmann et al. (2007) o alongamento da parte aérea e das raízes é dependente de divisões celulares, da formação do câmbio e dos vasos xilemáticos e essas estruturas são dependentes da partição de nutrientes pela plântula. Como para sorgo e picão preto, houve redução das raízes, então presupõe-se que estas estruturas foram afetadas por fitoconstituintes presentes no extrato. O sistema radicular 
das plantas é o mais sensível à ação de aleloquímicos porque o seu alongamento depende de divisões celulares que, se inibidas comprometem o seu desenvolvimento normal (HOFFMANN et al., 2007). Assim quanto menor o IVG, maior a dificuldade para a planta se alongar, conforme o observado neste trabalho, concordando com Alves et al. (2004) em relação ao comprimento da radícula e de plântulas de alface obtidas de sementes tratadas com óleos de canela, alecrim pimenta e capim citronela.

Figura 4 - Comprimento da raiz de Sorghum bicolor L., Lactuca sativa L.e Bidens pilosa L. submetidas a diferentes concentrações de extrato acetato-etílico de folhas de Solanum cernuum

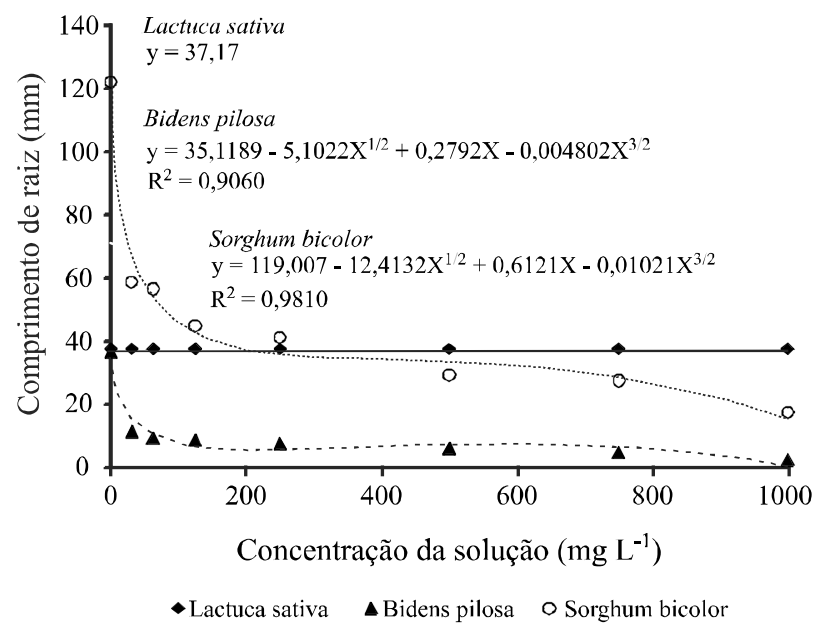

Na Figura 5 verifica-se que a massa seca das três espécies não sofreu interferência quando comparado com o controle, apesar do extrato ter mostrado efeito inibitório no crescimento de parte aérea (Figura 3) e raízes (Figura 4) das plântulas. Isto pode ser explicado pelo fato da presença do extrato ter causado aumento do diâmetro de hipocótilos e de raízes em algumas plântulas. Comportamento semelhante foi observado por Medeiros e Lucchesi (1993) que usando extrato aquoso de ervilhaca (Vicia sativa L.) verificaram redução no comprimento de raízes de alface sem no entanto aumentar a matéria seca das plântulas. Da mesma forma, Mazzafera (2003) trabalhando com extrato alcoólico de cravo-da-Índia (Syzygium aramaticum) não verificaram redução na matéria seca de parte aérea de plântulas de tomate e trigo, apesar do potencial germinativo ter sido grandemente afetado. No entanto, outros autores observaram redução da massa seca como Oliveira et al. (2011) no estudo alelopático do extrato aquoso das folhas de Emilia sonchifolia (L.) DC. (Asteraceae) observaram inibição significativa da massa seca, 32,9\% para Sorghum bicolor e 56,9\% para a espécie Bidens pilosa.

Figura 5 - Massa seca em plântulas de Sorghum bicolor L., Lactuca sativa L. e Bidens pilosa L. submetidas a diferentes concentrações de extrato acetato-etílico de folhas de Solanum cernuum

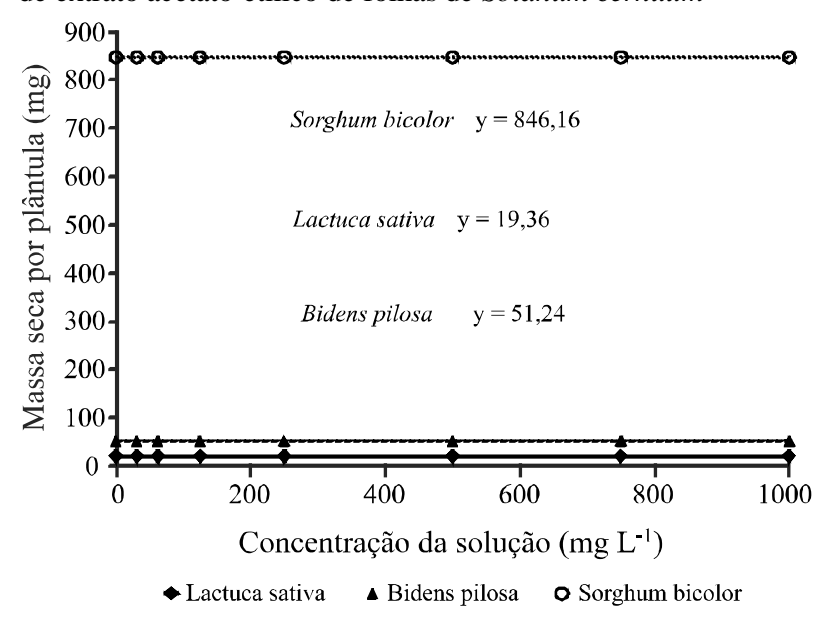

O presente trabalho corrobora a importância da pesquisa de plantas medicinais para se investigar seus efeitos alelopáticos e abrir perspectivas para a produção de substâncias naturais no controle de plantas daninhas.

\section{CONCLUSÕES}

1. Há efeitos fitotóxicos do extrato com acetato-etílico de Solanum cernuum Vell sobre a germinação de sementes e o vigor de plântulas de Sorghum bicolor L., Lactuca sativa L. e Bidens pilosa L.;

2. Dentre as espécies estudadas, B. pilosa é a mais sensível, com redução de $69 \%$ no comprimento da parte aérea e $88 \%$ no comprimento de raízes na presença de extrato de $S$. cernuum a $100 \mathrm{mg} \mathrm{L}^{-1}$.

\section{AGRADECIMENTOS}

Os autores agradecem à CAPES, FAPES, CNPq, BNB e UFES (PROEX e PRPPG) pelas bolsas concedidas e pelo suporte financeiro.

\section{REFERÊNCIAS}

ALVES, M. C. S. et al. Alelopatia de extratos voláteis na germinação de sementes e no comprimento da raiz de alface. 
Pesquisa Agropecuária Brasileira, v. 39, n. 11, p. 10831086, 2004.

AZAMBUJA, N. et al. Potencial alelopático de Plectranthus barbatus Andrews na germinação de sementes de Lactuca sativa L. e de Bidens pilosa L. Revista de Ciências Agroveterinárias, v. 9, n. 1, p. 66-73, 2010.

BELINELO, V. J. et al. Alelopatia de Arctium minus Bernh (Asteraceae) na germinação e crescimento radicular de sorgo e pepino. Caatinga, v. 21, n. 4, p. 12-16, 2008.

BORGES, F. C. et al. Potencial alelopático de duas neolignanas isoladas de folhas de Virola surinamenses (Myristicaceae). Planta Daninha, v. 25, n. 1, p. 51-59, 2007.

BRASIL. Ministério da Agricultura, Pecuária e Abastecimento. Regras para análise de sementes. Brasília, DF: MAPA/ACS, 2009. 395 p.

BRASS, F. E. B. Análise de atividade alelopática de extrato aquoso de falsa murta sobre a germinação de picão-preto e caruru. Enciclopédia Biosfera, v. 5, n. 8, p. 1-19, 2009.

CARMO, F. M. S.; LIMA, E. E.; TAKAKI, M. Alelopatia de extratos aquosos de canela-sassafrás (Ocotea odorifera (Vell.) Rohwer). Acta Botanica Brasílica, v. 21, n. 3, p. 697705, 2007.

CORSATO, J. M. et al. Efeito alelopático do extrato aquoso de folhas de girassol sobre a germinação de soja e picão-preto. Semina: Ciências Agrárias, v. 31, n. 2, p. 353-360, 2010.

COSTA, F. A. P. L. Demografia foliar: contando folhas no braço-de-preguiça, La Insígnia. Brasil, 2004.

FERREIRA M. C.; SOUZA J. R. P.; FARIA T. J. Potenciação alelopática de extratos vegetais na germinação e no crescimento inicial de picão-preto e alface. Ciência e Agrotecnologia, v. 31, n. 4, p. 1054-1060, 2007.

FERREIRA, E. G. B. S. et al. Efeito alelopático do extrato aquoso de sabiá na germinação de sementes de fava. Revista Ciência Agronômica, v. 41, n. 3, p. 463-467, 2010.

HAIDA, K. S. et al. Efeito alelopático de Achillea millefolium L. sobre sementes de Lactuca sativa L. Revista em Agronegócios e Meio Ambiente, v. 3, n. 1, p. 101-109, 2010.

HOFFMANN, C. E. F. et al. Atividade alelopática de Nerium Oleander L. e Dieffenbachia picta schott em sementes de Lactuca Sativa L. e Bidens pilosa L. Revista de Ciências Agroveterinárias, v. 6, n. 1, p. 11-21, 2007.
JÁCOME, R. L. R. P. et al. Caracterização farmacognóstica de Polygonum hydropiperoides Michaux e P. spectabile Mart. (Polygonaceae). Revista Brasileira de Farmacognosia, v. 14, n. 1, p. 21-27, 2004.

MACHADO, K. Z.; PIZZOLATI, M. G.; BRINGHENTE, I. M. C. Efeito alelopático de plantas ornamentais tóxicas. In: ENCONTRO DE QUÍMICA DA REGIÃO SUL, 11., 2003, Pelotas. Resumos... Pelotas: UFPEL, 2003. p. 115.

MAGIERO, E. C. et al. Efeito alelopático de Artemisia annua L. na germinação e desenvolvimento incial de plântulas de alface (Lactuca sativa L.) e leiteiro (Euphorbia heterophylla L.). Revista Brasileira de Plantas Medicinais, v. 11, n. 3, p. 317-324, 2009.

MAGUIRE, J. D. Speed of germination-aid in selection evaluation for seedling emergence and vigour. Crop Science, v. 2, p. 176-177, 1962.

MAZZAFERA, P. Efeito alelopático do extrato alcoólico do cravo-da-índia e eugenol. Revista Brasileira de Botânica, v. 26, n. 2, p. 231-238, 2003.

MEDEIROS, A. R. M. de; LUCCHESI, A. A. Efeitos alelopáticos da ervilhaca (Vicia sativa L.) sobre a alface em testes de laboratório. Pesquisa Agropecuária Brasileira, v. 28, n. 1, p. 9-14, 1993.

OLIVEIRA, L. G. A. et al. Alelopatia de Emilia sonchifolia (L.) DC. (Asteraceae) na germinação e crescimento inicial de sorgo, pepino e picão preto. Enciclopédia Biosfera, v. 7, n. 12, p. 1-9, 2011.

RICE, E. L. Allelopathy. 2. ed. New York: Academic Press, 1984. 422 p.

RICKLI, H. C. et al. Efeito alelopático de extrato aquoso de folhas de Azadirachta indica A. Juss. em alface, soja, milho, feijão e picão-preto. Semina: Ciências Agrárias, v. 32, n. 2, p. 473-484, 2011.

ROSADO, L. D. S. et al. Alelopatia do extrato aquoso e do óleo essencial de folhas do manjericão 'Maria Bonita' na germinação de alface, tomate e melissa. Revista Brasileira de Plantas Medicinais, v. 11, n. 4, p. 422-428, 2009.

SOUZA, S. A. M. et al. Efeito de extratos aquosos de plantas medicinais nativas do Rio Grande do Sul sobre a germinação de sementes de alface. UEPG - Ciências Biológicas e da Saúde, v. 11, n. 3, p. 29-38, 2005.

TEIXEIRA, C. M.; ARAÚJO, J. B. S.; CARVAlHO, G. J. Potencial alelopático de plantas de cobertura no controle de picão-preto (Bidens pilosa L.). Ciência Agrotecnologica, v. 28, n. 3, p. 691-695, 2004. 